
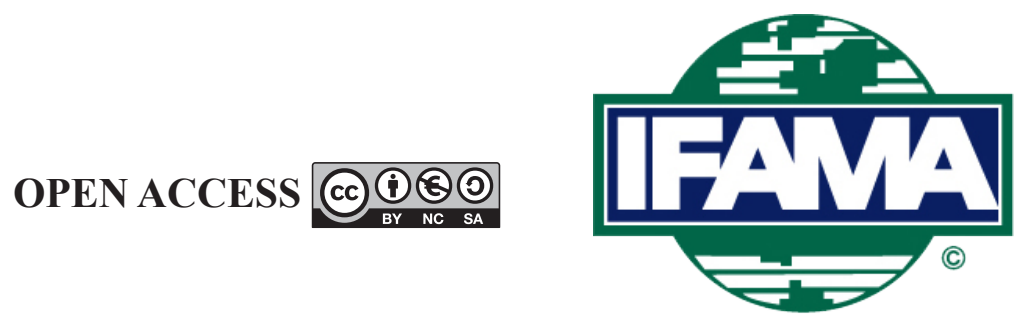

International Food and Agribusiness Management Review

Volume 23, Issue 3, 2020; DOI: 10.22434/IFAMR2019.0151

Received: 18 September 2019 / Accepted: 15 May 2020

\title{
Farmer awareness, perceptions and adoption of unmanned aerial vehicles: evidence from Missouri \\ RESEARCH ARTICLE
}

\author{
Theodoros Skevas $^{\circledR \mathrm{a}}$ and Nicholas Kalaitzandonakes ${ }^{\mathrm{b}}$ \\ ${ }^{a}$ Assistant Professor, ${ }^{b}$ Professor, Division of Applied Social Sciences, University \\ of Missouri, 124 Mumford Hall, Columbia, MO 65211, USA
}

\begin{abstract}
Unmanned Aerial Vehicles (UAVs) are expected to play an important role in the future of farming. Because UAVs can provide precise, real-time information on biotic and abiotic stressors in agricultural production while they can also carry out autonomous operations to counter them, they can enhance farm profitability while reducing the environmental footprint of agriculture. Yet little is known about the current adoption of UAVs in agriculture or about the profile of the adopters. In this study we report actual and expected adoption of UAVs for a rich cross section of crop farmers and examine the factors that shape such adoption. In our empirical analysis we describe the inherent farmer heterogeneity - as shaped by differential awareness of UAV applications, perceptions of technical complexities, expectations of economic and environmental benefits and various socioeconomic factors - and analyze which of all these factors shape individual farmer adoption of UAVs. We also estimate and describe a small number of farmer segments that might adequately describe general population tendencies in the adoption of UAVs.
\end{abstract}

Keywords: agricultural innovation, technology awareness, technology adoption, Unmanned Aerial Vehicles JEL code: Q12, Q16, O14, O33, D22

(i)Corresponding author: skevast@missouri.edu 


\section{Introduction}

Unmanned Aerial Vehicles (UAVs) were originally developed for military applications. More recently, their use has been extended to other commercial applications, including agricultural operations, especially precision agriculture programs. UAVs are expected to play an important role in the future of farming. UAVs' ability to fly under diverse weather conditions, at low operating cost and with limited manpower while providing high spatial and temporal resolution images and other sensing data (Floreano and Wood, 2015; Pritt, 2014; Schirrmann et al., 2016) makes them a promising precision farming technology, perhaps preferred over other competing technologies such as satellites and manned aircraft. Because UAVs can provide precise, real-time information on biotic and abiotic stressors in agricultural production while they can also carry out autonomous operations to counter them, they can enhance farm profitability while reducing the environmental footprint of farming (Walter et al., 2017). Such economic and environmental gains are particularly important in the face of a growing world population, climate change and other environmental pressures, low commodity prices and compressed farming margins, all of which demand increased agricultural productivity and sustainability.

Research on the use of UAVs in agriculture has focused on two main areas: the utility of UAVs in precision farming (e.g. Primicerio et al., 2012; Vega et al., 2015, and others); and the technical and regulatory challenges in their use (Aldana-Jague et al., 2016; Freeman and Freeland, 2014, 2015; Huang et al., 2013; Morley et al., 2017; Potts et al., 2018). Studies in the first area show that UAVs can be used effectively deployed in a wide range of agricultural applications including pest and disease control (Psirofonia et al., 2017); monitoring and mapping of soil properties (d'Oleire-Oltmanns et al., 2012; Huuskonen and Oksanen, 2018); monitoring of crop conditions and health (Panagiotidis et al., 2017); and irrigation management (Gago et al., 2015; Martınez et al., 2017). A few studies in this research area also show that UAVs can lead to economic gains and improved farm profitability (Duchsherer, 2018; West and Kovacs, 2017). Studies in the second research area conclude that while challenges such as payload capacity and flight time restrictions as well as aviation constraints and other regulatory uncertainties remain, it is likely that these will be overcome in the near future with technical advances and improved regulations (Morley et al., 2017; Zhang and Kovacs, 2012). Overall, the findings of these two strands of literature suggest a promising future for the development and use of UAVs in agriculture. However, as with other agricultural innovations, the adoption of UAVs on the farm will be conditioned by many factors including farmer awareness of their potential uses, farmer perceptions of ease of use, farmer expectations of benefits and costs, as well as individual farmer and farm characteristics (Tey and Brindal, 2012).

Presently, there is limited evidence on the awareness, perceptions and socioeconomic profile of the farmers that adopt UAVs. In fact, there is limited evidence on the overall farm-level adoption of UAVs, altogether. Erickson and Lowenberg-DeBoer (2017) surveyed 209 agricultural retailers who supply precision agriculture services to farmers operating in 29 US states. As part of the survey, retailers reported on the share of acres that used UAV imagery, which was 6\% in 2017. Thompson et al. (2019) surveyed large US farmers (with crop acreage of 1000 acres or more) about their adoption of various precision farming technologies. They found that $25 \%$ of this group of farmers used UAVs, in some way, in their operations. These two studies, however, did not examine the factors behind the levels of UAV adoption they reported. Zheng et al. (2019) surveyed farmers' stated willingness to adopt UAVs for pesticide applications in a Chinese province and concluded that most farmers were willing to adopt them for that purpose. They also found that perceived ease of use and usefulness of the technology were the most important factors that affected farmers' willingness to adopt UAVs.

Our study contributes to the small existing literature by reporting actual and expected adoption of UAVs for a rich cross section of crop farmers as well as by examining the factors that shape such adoption. The empirical application focuses on a sample of 809 Missouri farmers surveyed in 2018. In our empirical analysis we first examine farmer awareness and perceptions of ease of use, potential benefits and constraints to the adoption of UAVs. Next, we identify farmer segments with distinct perceptions and socioeconomic profiles and we describe their differential proclivities to adopt UAVs. Finally, we link adoption levels to 
individual farmer information, perceptions and socioeconomic characteristics. The results of our study show that adoption of UAVs among Missouri farmers is still at early stages. Farmers' expectations of economic or environmental benefits, costs of adoption, technical complexities but also perceptions about privacy concerns that neighbors may harbor, are all found to influence adoption. Our empirical results also indicate that there might be significant latent demand for UAV adoption and we discuss the factors that may encourage such demand to materialize.

\section{Data and empirical methods}

\subsection{Respondent sampling and survey methods}

Data for this study came from a 2018 mail survey of Missouri farmers who owned 100 or more acres of agricultural land. Since comprehensive producer lists were not available at the state or county level (making random sampling impossible), selection of the study sample was carried out in two stages. In the first stage we used the 2012 Census of Agriculture to select counties in the state of Missouri with at least 140,000 acres of combined corn and soybean acreage (the two major crops in the state). We made this selection to avoid sampling counties with minimal agricultural activity. Twenty-four counties exceeded the threshold and were grouped into four geographic clusters of six counties representing regions where arable farming is the main agricultural activity in the State (i.e. northwest, central-west, central-east, and southeast). We used this stratification to ensure that the main agricultural areas in Missouri would be well-represented in the final dataset. From each cluster, three counties were selected at random to create a manageable data set. The selected counties were Atchison, Carroll, Chariton, Harrison, Lafayette, Lincoln, New Madrid, Nodaway, Pemiscot, Pike, Ralls, and Stoddard. In the second stage we contacted the assessor offices of the selected counties to obtain property tax records of individuals who owned 100 or more acres of land listed as agricultural/horticultural for property tax purposes. ${ }^{1}$ All property owners in each county-specific list were assigned a random number and the first 250 random numbers were selected for participation. The sampling process resulted in a total of 3,000 potential respondents.

The survey included questions on land management practices, use of UAVs in agricultural operations, farmer awareness and perceptions of UAV uses, expected benefits, as well as farmer socioeconomic characteristics. In the land management section, respondents were asked how much land they owned of each of the following types: agricultural cropland, farmable non-cropland, and other (e.g. wetlands, forest). Respondents were also asked whether they currently rented in or rented out any portion of their land and whether they exchanged information or coordinated with neighboring farmers on cropping practices that could affect them mutually (e.g. planting dates, spray dates, etc.). In the next section, respondents were asked whether they were using or were planning to use a UAV in their farming operations. Awareness and perceptions on the potential applications and impacts of UAVs in agricultural production were elicited through both dichotomous questions and a series of statements with which respondents indicated the extent of their agreement or disagreement on a scale of 1 (strongly disagree) to 5 (strongly agree). To measure awareness about potential UAV uses in agriculture, respondents were asked whether they had heard or read about UAVs being used to: evaluate plant health, monitor disease or insect outbreaks, apply agrochemicals, or monitor plant hydration and nutrient uptake. Finally, respondents were asked questions about their age, gender, education, cooperative membership, household income, and about the presence of a successor for their farm.

The survey was executed following Dillman et al. (2011) total design method. Four mailings were sent out during 2018 in the following sequence: (1) pre-survey postcard to inform the subjects (February 23); (2) first survey mailing (March 3); (3) reminder postcard (March 12); and (4) second survey mailing to non-respondents to the first round of mailing (March 23). Of the 3,000 questionnaires mailed, 157 were

\footnotetext{
${ }^{1}$ Agricultural/horticultural is one of the three classifications (for tax assessment purposes) of real property in Missouri, the others being residential, and utility, industrial, commercial, railroad, and all other. The agricultural/horticultural property tax records include not only active farmers but also landowners of non-cropland such as grasslands and forests. Therefore, the first-stage selection of top counties in terms of area of the two major crops in the state increased the likelihood of getting property tax records that included a high number of active farmers.
} 
returned as undeliverable. Of the remaining 2,843, 946 were returned, for a total response rate of $33 \%$. Of these, 137 were unusable primarily because the respondents did not meet the basic eligibility requirements for participation. This resulted in a total of 809 usable responses, and an adjusted response rate of $28 \%$. Descriptive statistics of our survey sample are reported in Table 1.

\subsection{Empirical methods}

In our empirical analysis we examined how current adoption or prospective adoption of UAVs is shaped by farmer awareness, perceptions, socioeconomics and farm characteristics. We used three types of empirical models: factor analysis to distill key farmer perceptions towards UAVs; cluster analysis to identify farmer segments with distinct perceptions, socioeconomic profiles and propensity to adopt UAVs; and logistical regression analysis to examine specific factors that shape the individual farmer decision to adopt UAVs.

\section{- Factor analysis and farmer perceptions}

In order to better understand farmer perceptions of UAV uses and impacts, factor analysis was used. More specifically, factor analysis was applied to summarize a number of interrelated perception variables into a smaller number of underlying factors that explain most of the variance in the larger set of the measured variables. The process of factor analysis involves three steps: (1) extraction of factors from a correlation matrix, using principal component analysis; (2) rotation of the factors, resulting in elucidation of factors; and (3) interpretation of the factors. Two criteria were employed for determining a factor solution: minimum factor eigenvalues of 1.0; and exclusion of items with factor loadings less than 0.60. The eigenvalue and the factor loading reflect the amount of variance accounted for by a factor and the correlation between a variable and a factor, respectively. Following the identification and explanation of the factors, we used Cronbach's alpha statistics to ensure their internal consistency.

\section{- Cluster analysis and farmer segments}

Based on the results of the factor analysis, we used non-hierarchical cluster analysis (K-means) to identify groups of farmers with similar perceptions, personal profiles and propensity to adopt UAVs. The K-means cluster analysis, which is a form of a centroid based clustering, groups respondents into k distinct clusters by minimizing within-cluster variance and maximizing variability among clusters (Kaufman and Rousseeuw, 2009). After the clusters were identified, we used ANOVA tests to describe the typical farmer profile in each

Table 1. Descriptive statistics of surveyed farmers. ${ }^{1}$

\begin{tabular}{llll}
\hline Variable & Units & Mean & Standard deviation \\
\hline Rented out land in 2017 & $(0 / 1)$ & 0.45 & 0.50 \\
Rented in land in 2017 & $(0 / 1)$ & 0.34 & 0.48 \\
Raised livestock on the farm in 2017 & $(0 / 1)$ & 0.44 & 0.50 \\
Area of farmland & Acres & 852.42 & $1,070.28$ \\
Land in Conservation Reserve Program & $(0 / 1)$ & 0.24 & 0.43 \\
Age & years & 65.45 & 13.06 \\
Male gender & $(0 / 1)$ & 0.86 & 0.35 \\
Farmer is a member of a cooperative & $(0 / 1)$ & 0.47 & 0.50 \\
Collective earnings of household members in 2017 & $1-6$ & 3.49 & 1.31 \\
Education & $1-6$ & 3.20 & 1.33 \\
Availability of successor & $(0 / 1)$ & 0.50 & 0.50 \\
\hline
\end{tabular}

${ }^{1}$ The collective earnings of household members variable is scaled from $1(<\$ 25,000)$ to $6(\geq \$ 200,000)$ and includes income from both farm and off-farm sources. The education variable is scaled from 1 ( $<12$ years of education) to 6 (graduate degree). 
cluster and to map how farmer socioeconomic characteristics, crop management practices and willingness to use UAVs differ across these clusters.

\section{- Multinomial regression analysis of farmer adoption decision}

In order to understand the factors that influence farmer UAV adoption decision, multinomial regression analysis was used. This analysis is appropriate when the dependent variable consists of three or more categories that are unordered and discrete. In this study the dependent variable $y$ has 3 categories, namely: non-adopters $(j=1)$, prospective adopters $(j=2)$, and current adopters $(j=3)$. Prospective adopters are those who may soon become adopters, while non-adopters are those who have no expressed plans to use UAVs. As it is common practice (e.g. Läpple and Van Rensburg, 2011), we use non-adopters as the reference category. This allows comparisons in the probabilities of membership in the current and prospective adopter categories to the probability of membership in the non-adopter category and the factors that drive them. The probabilities of the three categories are given by the equation below:

$$
P\left(y_{i}=s \mid x_{i}\right)=\frac{e^{\beta_{s} x_{i}}}{\sum_{j=1}^{J} e^{\beta_{j} x_{i}}}, j=1, \ldots, 3
$$

where $s$ denotes one of the three adoption categories, $P\left(y_{i}=s\right)$ is the probability that farmer $i$ belongs to the $s$ category, and $x_{i}$ denotes a vector of covariates that may affect a farmer's decision to adopt UAVs. To identify the multinomial logit model is necessary to impose the restriction that $\beta_{1}=0$ (Long et al., 2006). This allows an identification of the coefficients relative to the reference category. Imposing this restriction results in the following model:

$$
\begin{array}{r}
P\left(y_{i}=1 \mid x_{i}\right)=\frac{1}{1+\sum_{j=2}^{J} e^{\beta_{j} x_{i}}} \\
P\left(y_{i}=s \mid x_{i}\right)=\frac{e^{\beta_{s} x_{i}}}{1+\sum_{j=2}^{J} e^{\beta_{j} x_{i}}}, \text { for } s>1
\end{array}
$$

Maximum likelihood procedures were used to estimate the multinomial logit model (Long et al., 2006). The likelihood function used in the estimation is specified as:

$$
L\left(\beta_{2}, \ldots, \beta_{j} \mid y, x\right)=\prod_{s=1}^{j} \prod_{y_{i}=s} \frac{e^{\beta_{s} x_{i}}}{\sum_{j=1}^{J} e^{\beta_{j} x_{i}}}
$$

Relative risk ratios (RRRs) were then derived to interpret the coefficients. RRRs were calculated as the exponentiated values of the model coefficients:

$$
\frac{P(y=s)}{P(y=1)}=e^{\beta_{j} x_{i}} \text { for } s>1
$$

RRRs are interpreted as the change in the relative probability of $y_{i}=s$ for $s>1$ relative to the reference outcome for a one-unit change in the associated predictor. In general, relative risk ratios greater (less) than one indicates an increased (decreased) probability of the outcome occurring compared to the reference. As is obvious, an RRR for $s$ is computed without reference to the remaining two categories. This is known as the assumption of the independence of irrelevant alternatives (IIA), an assumption that is inherent in multinomial logit models. Formal tests for IIA are not conducted because their use is not recommended due to poor performance (Cheng and Long, 2007). Instead, following Amemiya (1981), we assumed that the multinomial logit model works well when the alternatives are obviously distinct. 


\section{Empirical results}

\subsection{Adoption of unmanned aerial vehicles}

From our survey data, we found that only $8 \%$ of the farmers in our sample were adopters and were currently using UAVs in their agricultural operations (Figure 1). This adoption level is significantly lower than the one reported by Thompson et al. (2019) who surveyed only very large farmers. A further $19 \%$ of the farmers in our sample indicated that they had plans to adopt UAVs in the near future - they were prospective adopters. The large majority (73\%) of the farmers in the sample, however, did not have immediate plans to use UAVs in their farm operations - they were non-adopters.

\subsection{Farmer awareness of unmanned aerial vehicle applications}

Farmers in the sample were generally aware of the different ways UAVs can be used in farming operations. In particular, responding to questions whether they had heard or knew of certain potential applications, a majority of farmers seemed well informed (Figure 2). More than $75 \%$ of the respondents were aware that UAVs can be used to evaluate plant health and monitor disease or insect outbreaks. Slightly fewer respondents were aware that UAVs can be used to apply agrochemicals or monitor plant hydration and nutrient uptake, 56 and $62 \%$ respectively. Almost half of the survey participants were aware of all four UAV agricultural applications included in the survey, while $18 \%$ had never heard of any of these UAV applications.

\subsection{Farmer perceptions of unmanned aerial vehicle costs, benefits and ease of use}

While a majority of the farmers in our sample was aware of the potential uses of UAVs in farming, a majority did not expect significant economic or environmental benefits from such uses. Specifically, $83 \%$ the respondents in our survey did not perceive that the use of UAVs can reduce farm input costs while $65 \%$ of them did not perceive UAVs can reduce the environmental footprint of farming (Figure 3 ). In addition to the tempered expectations about the potential gains from UAVs, a large majority of survey respondents were concerned or uncertain about the initial costs of acquiring UAVs, the knowledge required to operate them, the assistance needed to process and interpret the data collected through UAVs, and the ease of turning them into agronomic solutions for their farm (Figure 4). Farmer perceptions of difficulties and costs associated with the use of UAVs combined with perceptions of potentially limited efficiency and environmental gains would tend to limit farmer propensity to adopt UAVs.

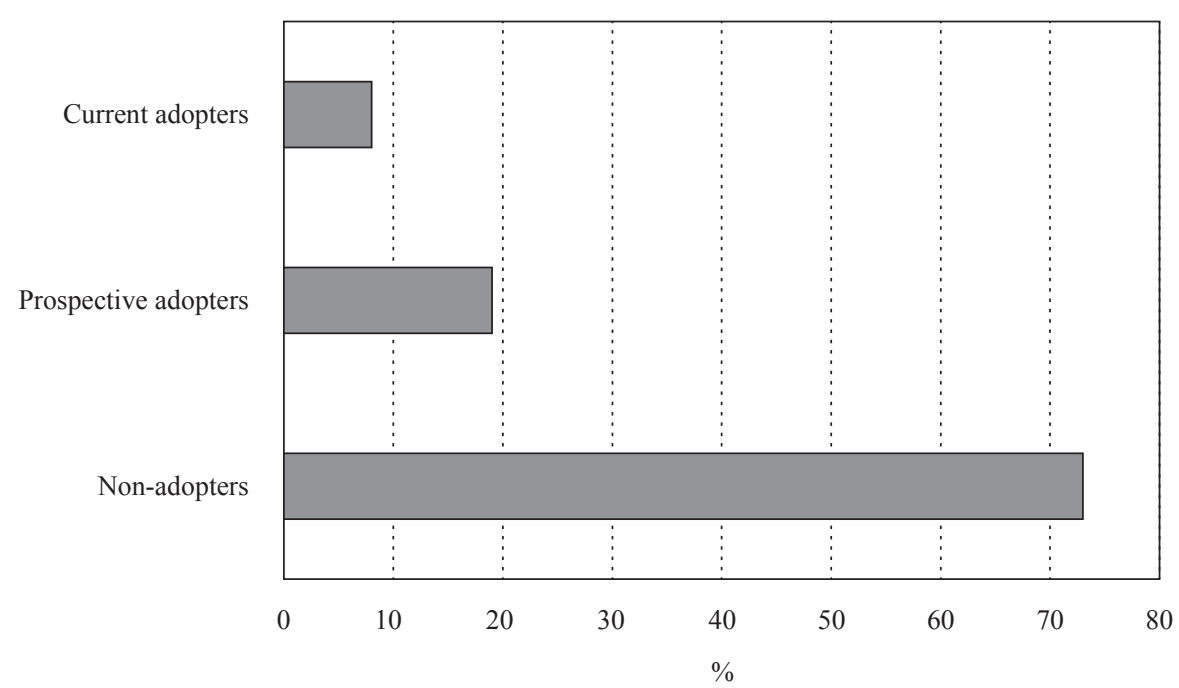

Figure 1. Farmer adoption of unmanned aerial vehicles. 


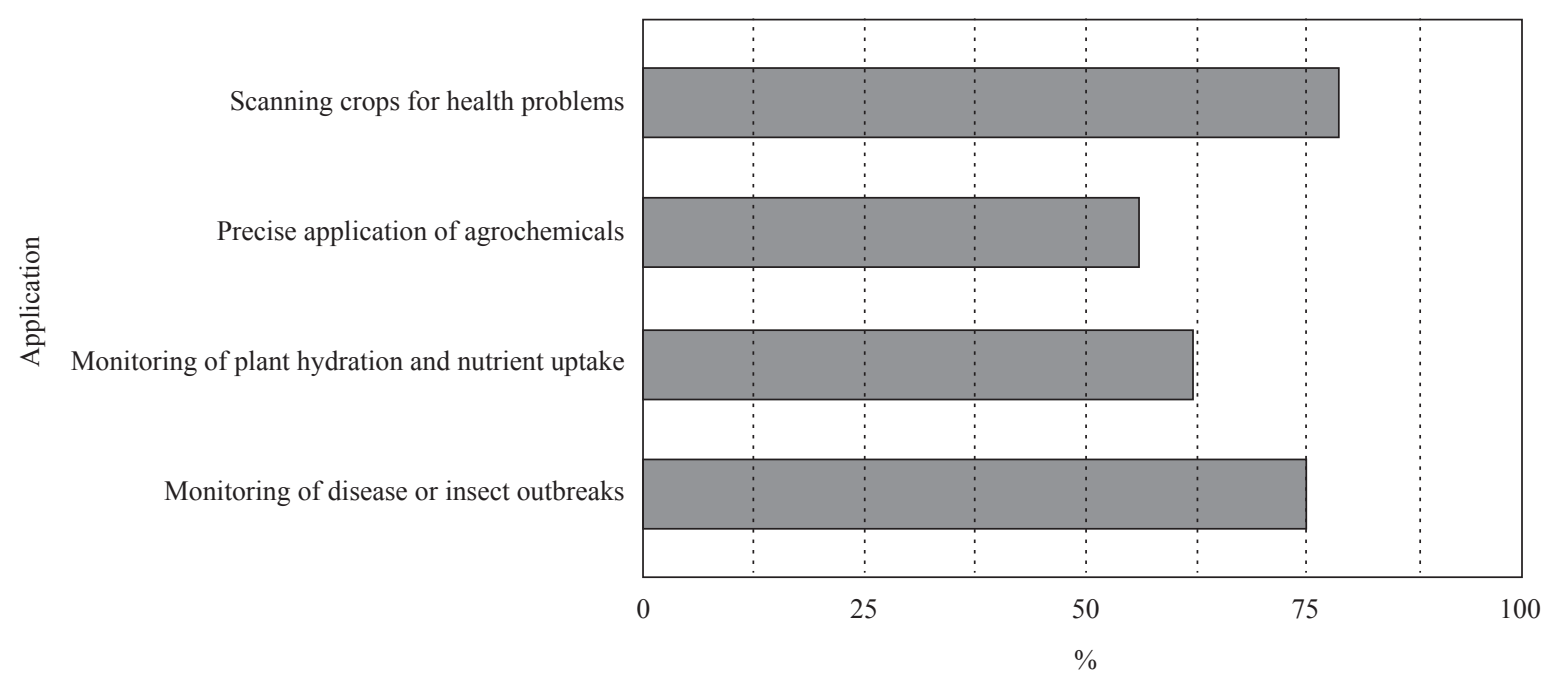

Figure 2. Farmer awareness of UAV applications in agriculture.
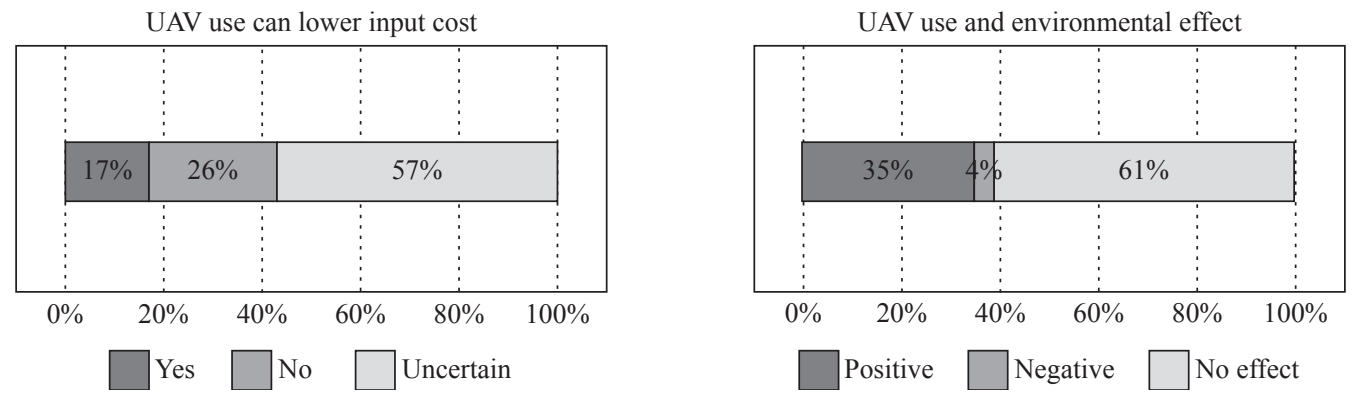

Figure 3. Farmer expectations of potential benefits of unmanned aerial vehicles.

An additional concern expressed by survey respondents that could also limit adoption was associated with the potential presence of externalities and associated social costs from the use of UAVs. Specifically, some $40 \%$ of the surveyed farmers stated they were apprehensive about potential privacy concerns their neighbors might harbor over their use of UAVs on their farm. It is not clear how strong such concerns were among the survey respondents, however as in a separate question when farmers were asked more directly how would their neighbors likely react to the use of UAVs on their farms (the options were 'very much appreciate', 'appreciate', 'indifferent', 'disapprove', and 'very much disapprove') a large majority (80\%) reported that their neighbors would be indifferent. These results suggest that a meaningful share of the farmers in our sample might consider potential neighbor privacy concerns troubling but such perceptions might not be strongly held when probed. 


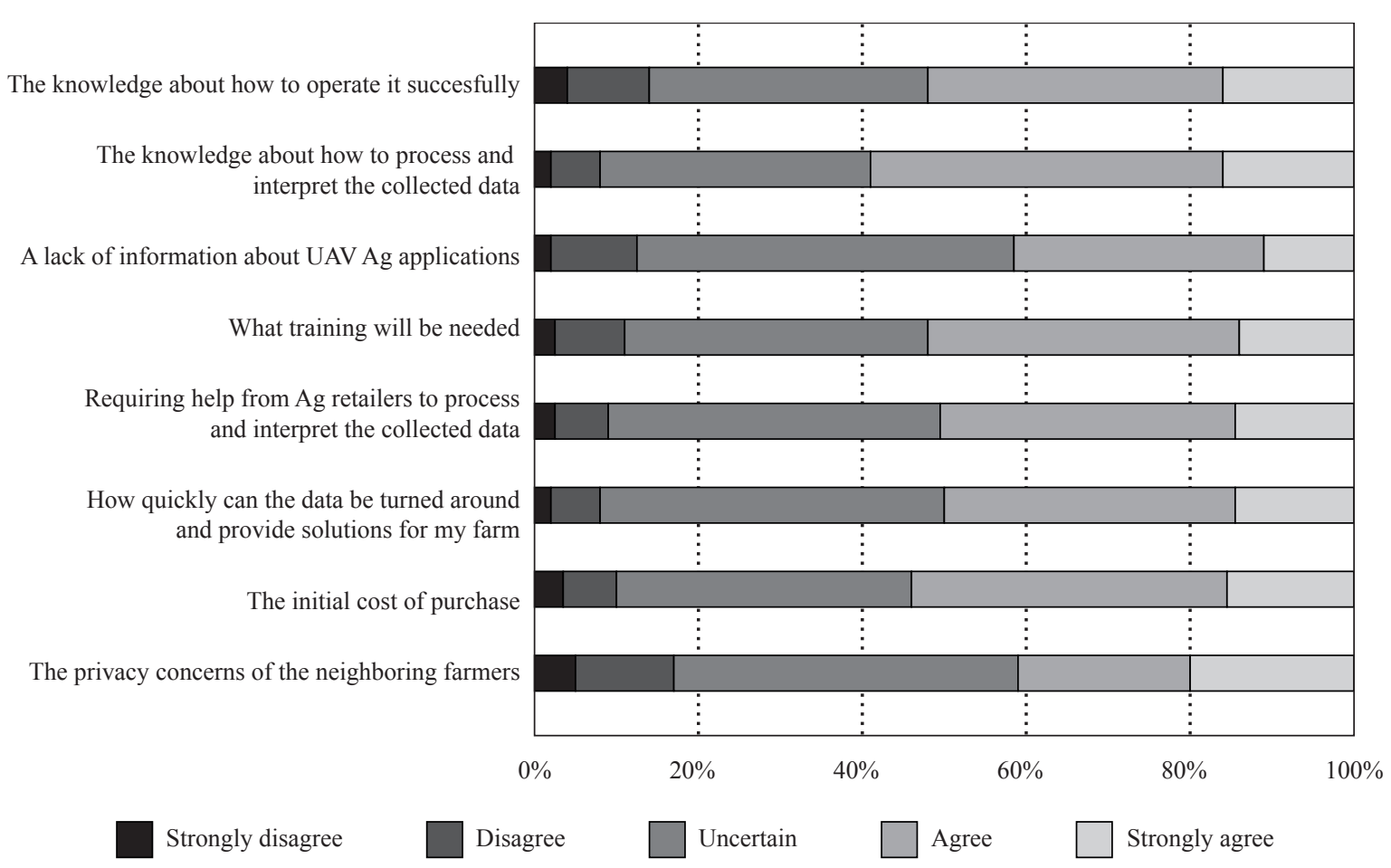

Figure 4. Farmer perceptions of unmanned aerial vehicle ease of use, initial costs and neighbor concerns. The exact wording preceding the statements of this figure is as following: 'When I think about using UAVs in my farm, I am concerned with...'.

\subsection{Factor analysis of farmer awareness and perceptions}

In order to distill the various overlapping perception and awareness statements into some key factors that might have independent and separate influences on farmer adoption behavior, we used factor analysis ${ }^{2}$. The results are reported in Table 2 and indicate that there are three factors underlying the awareness and perceptions of the survey respondents towards the use of UAVs in agriculture. The three-factor solution was chosen on the basis of multiple criteria including Kaiser's criterion (eigenvalue of $\geq 1$ ), and conceptual interpretability. Examination of the eigenvalues exceeding one supported this decision. This solution explained about $66 \%$ of the common variance, with factor 1 accounting for $35 \%$, factor 2 for $22 \%$, and factor 3 for $9 \%$. In order to assess the internal consistency of each factor, Cronbach's alpha values were computed. These values exceeded 0.7 , verifying the homogeneity of each factor.

The labels of the three factors were based on the items which loaded 0.6 or greater on each factor. The first factor, which we named 'complexity in use' (CIU) factor, had high loadings on questions related to perceived initial implementation costs, ease of use and necessary knowledge required to effectively employ UAVs. The second factor, which we called 'UAV awareness' (UA), had high loadings on questions related to farmer understanding and awareness of potential applications of UAVs in agriculture. Finally, the third factor had high loadings on farmer perceptions of potential neighbor privacy concerns, so we termed the factor 'concerns of neighbors' $(\mathrm{CN})$ factor. A factor value was calculated for each respondent on each factor.

\footnotetext{
${ }^{2}$ Factor analysis was also used to reduce the number of a set of interrelated variables related to farmer coordination with neighbors on cropping practices. The results of this analysis are reported in Supplementary Table S2.
} 
Table 2. Rotated factor loadings.

\begin{tabular}{|c|c|c|c|c|}
\hline No. & Variable $^{1}$ & $\mathrm{CIU}^{2}$ & $\mathbf{U A}^{2}$ & $\mathrm{CN}^{2}$ \\
\hline 1 & The initial cost of purchase & 0.686 & 0.029 & 0.008 \\
\hline 2 & The knowledge about how to operate it successfully & 0.823 & -0.024 & -0.031 \\
\hline 3 & What training will be needed & 0.851 & 0.009 & 0.012 \\
\hline 4 & The knowledge about how to process and interpret the collected data & 0.847 & 0.091 & 0.029 \\
\hline 5 & $\begin{array}{l}\text { How quickly can the data be turned around and provide solutions for } \\
\text { my farm }\end{array}$ & 0.824 & 0.078 & 0.030 \\
\hline 6 & A lack of information about the use of $\mathrm{UAVs}^{2}$ in farming applications & 0.625 & -0.052 & 0.476 \\
\hline 7 & $\begin{array}{l}\text { Requiring help from agricultural retailers or other commercial } \\
\text { vendors to process and interpret the collected data }\end{array}$ & 0.715 & 0.012 & 0.264 \\
\hline 8 & Privacy concerns of neighboring farmers & 0.500 & -0.013 & 0.615 \\
\hline 9 & Would your neighbors appreciate if you use a UAV on your plot? & -0.110 & -0.124 & 0.805 \\
\hline 10 & Scanning crops for health problems & 0.054 & 0.884 & -0.107 \\
\hline 11 & Locating disease or insect outbreaks & 0.042 & 0.884 & -0.059 \\
\hline 12 & Applying fertilizer and pesticides more precisely & 0.007 & 0.732 & 0.031 \\
\hline 13 & Monitoring plant hydration and nutrient uptake & -0.010 & 0.833 & 0.002 \\
\hline
\end{tabular}

\subsection{Cluster analysis and farmer segmentation}

Next, we used cluster analysis to examine whether the estimated factors enabled effective farmer segmentation. The optimal number of clusters was determined by evaluating the Calinski and Harabasz pseudo-F index (Calinski and Harabasz, 1974). This index increased as more clusters were added, but decreased after the fourth cluster. Therefore, four clusters were considered appropriate. The four identified clusters and the number of farmers in each cluster are presented in Table 3. The four clusters carry cluster membership of 9 , 42,31 and $18 \%$ of the 809 farmers included in the study.

The identified clusters can be labeled using the cluster means of the original questions (Supplementary Table S1), the cluster means of the factor scores, or both. Since assigning a label to each cluster based on individual statements is not straightforward, we calculated and compared the factor mean scores across all clusters using ANOVA, as shown in Table 4. The ANOVA test results (F-statistics) show that there is significant inter-cluster heterogeneity on the importance of the three factors that represent farmer perceptions and awareness in the sample.

Table 3. Percentage of cases in each cluster.

\begin{tabular}{lc}
\hline Cluster number & Percentages $^{1}$ \\
\hline 1 & $9.52(77)$ \\
2 & $41.53(336)$ \\
3 & $30.53(247)$ \\
4 & $18.42(149)$ \\
\hline${ }^{1}$ Numbers in parentheses represent the number of respondents.
\end{tabular}


Table 4. Farmers' cluster membership and mean factor deviations.

\begin{tabular}{llllll}
\hline & \multicolumn{2}{c}{ Clusters } & & F-statistic $^{\mathbf{1}}$ \\
\cline { 2 - 5 } & Cluster 1 & Cluster 2 & Cluster 3 & Cluster 4 & \\
\hline $\mathrm{CIU}^{2}$ & 0.169 & 0.697 & -0.872 & -0.213 & $215.27^{* * * *}$ \\
$\mathrm{UA}^{2}$ & -0.234 & 0.431 & 0.521 & -1.714 & $647.70^{* * *}$ \\
$\mathrm{CN}^{2}$ & 2.22 & -0.262 & -0.192 & -0.237 & $290.47^{* * *}$ \\
\hline $1^{* * *}$ significant at the 1\% level. & & & \\
${ }^{2} \mathrm{CIU}, \mathrm{UA}$, and CN denote complexity in use, UAV awareness, and concerns of neighbors, respectively.
\end{tabular}

For CIU, higher positive scores indicate higher levels of concern about the complexity of using UAVs in farming due to the perceived knowledge requirements in operating them and interpreting the collected data. Similarly, for $\mathrm{CN}$ high positive scores indicated increased apprehension about neighboring farmer harboring privacy concerns. For UA, higher positive values indicate increased awareness of the potential applications of UAVs in agricultural prodtuction. Given these, cluster 1 was labelled 'neighbor-warry' as it had by far the highest $\mathrm{CN}$ score of the four clusters. Respondents in this cluster expressed modest concern regarding the complexity in the use of UAVs and were uncertain about their applicability in agriculture. Cluster 2 had the second highest UA score and the highest CIU score. These results imply that respondents in cluster 2 were aware of UAV agricultural applications but perceived UAV operations and data interpretation challenging. Cluster 2 was therefore labeled 'UAV complexity warry'. Cluster 3 had the highest score for UA, implying that respondents of this cluster were more aware of UAV agricultural applications than farmers in other clusters. In addition, respondents in cluster 3 did not perceive using UAVs and processing the collected data as challenging (cluster 3 had the lowest score for CIU). Cluster 3 was therefore labeled 'UAV technology savvy'. Finally, cluster 4 had by far the lowest UA score of the four clusters, implying its respondents were the least aware of UAV agricultural applications. Respondents in this cluster also expressed few concerns about complexity in the use of UAVs or about their neighbors' reaction to the potential use of UAVs. For this last cluster, the label 'UAV technology detached' was used.

In order to further enrich the profiles of the four farmer segments, we used ANOVA applied to the farmers' socioeconomic characteristics and their UAV adoption behavior. The results, presented in Table 5, show that 16 variables were significantly different across the four clusters. These variables were: rent out, rent in, livestock, farmland, age, male, coop, income, education, successor, cooperates with neighbors, non-adopters, current adopters, and prospective adopters.

Farmers belonging to the neighbor warry segment were found to have the following characteristics: they were more likely to rent out land and raise livestock on their farms; they were less likely to rent in land or cooperate with neighboring farmers on production issues; they were, on average, smaller farmers in terms of acreage; they were mostly male; they were less likely to be members of a cooperative or a farmer group; they had the lowest education and income levels of all groups; they were the least likely to have a successor for their farm; they were the most likely of all groups to perceive that the use of UAVs would not reduce input costs or enhance environmental quality; and they were more likely to belong to the non-adopter group.

Farmers belonging in the UAV complexity warry segment were found to have the following characteristics: they were less likely to rent out land and more likely to rent in land in their operations; they were more likely to raise livestock on their farms; they operated larger farms, were heavily male and were more likely to be members of a cooperative or farmer group. Farmers in this segment were also more likely to have high family income, be highly educated, and to cooperate with neighbors on cropping practices that might affect them jointly. Farmers in this segment were also more likely to expect economic and environmental benefits from the use of UAVs in farming. Finally, farmers in this segment were more likely to be current or prospective adopters of UAVs. 
Table 5. Socioeconomic characteristics by cluster (mean scores). ${ }^{1}$

\begin{tabular}{lccccc}
\hline & Neighbor-warry & $\begin{array}{l}\text { UAV complexity } \\
\text { warry }\end{array}$ & $\begin{array}{l}\text { UAV technology } \\
\text { savvy }\end{array}$ & $\begin{array}{l}\text { UAV technology } \\
\text { detached }\end{array}$ & F-statistic \\
\hline Rent_out & 0.532 & 0.414 & 0.445 & 0.517 & $2.19^{*}$ \\
Rent_in & 0.234 & 0.417 & 0.372 & 0.201 & $9.00^{* * *}$ \\
Livestock & 0.571 & 0.440 & 0.421 & 0.409 & $2.11^{*}$ \\
Farmland & 479.458 & $1,015.054$ & 942.515 & 529.054 & $11.23^{* * *}$ \\
CRP & 0.247 & 0.238 & 0.211 & 0.295 & 1.23 \\
Age & 68.312 & 64.030 & 63.858 & 69.819 & $9.64^{* * *}$ \\
Male & 0.792 & 0.884 & 0.899 & 0.758 & $6.77^{* * *}$ \\
Coop & 0.364 & 0.536 & 0.518 & 0.309 & $9.32^{* * *}$ \\
Household income & 2.961 & 3.762 & 3.526 & 3.087 & $14.37^{* * *}$ \\
Education & 2.935 & 3.313 & 3.219 & 3.060 & $2.40^{* *}$ \\
Successor & 0.377 & 0.530 & 0.518 & 0.450 & $2.57^{* *}$ \\
Cooperates with & -0.344 & 0.197 & 0.090 & -0.416 & $20.50^{* * *}$ \\
neighbors & & & & \\
UAV-environment & 0.052 & 0.485 & 0.360 & 0.174 & $28.41^{* * *}$ \\
UAV-input cost & 0.000 & 0.247 & 0.182 & 0.060 & $15.05^{* * *}$ \\
Non-adopters & 0.961 & 0.667 & 0.664 & 0.879 & $17.79^{* * *}$ \\
Current adopters & 0.000 & 0.107 & 0.101 & 0.013 & $7.15^{* * *}$ \\
Prospective adopters & 0.039 & 0.226 & 0.235 & 0.107 & $8.27^{* * *}$ \\
\hline 1*****, and ${ }^{*}$ indicate that the estimate is significantly different from zero at the 1,5 and $10 \%$ significance level, respectively. CRP \\
= Conservation Reserve Program; UAV = unmanned aerial vehicles. & & &
\end{tabular}

Farmers belonging in the UAV technology savvy segment were found to have the following characteristics: they were more likely to rent in land and own larger-size farms; they were less likely to raise livestock on their farms; they were, on average, the youngest among the four groups and dominantly male; they were likely to have a successor and most likely to be a member of a cooperative or farmer group; they were more likely to have high family income; and they were more highly educated. Farmers in this segment were more likely to expect economic and environmental benefits from UAV use and were equally likely be current and prospective adopters of UAVs as farmers in the UAV complexity warry segment.

Finally, farmers in the UAV technology detached segment were found to have the following characteristics: they were more likely to rent out land and less likely to rent in land; they were less likely to raise livestock on their farm; they had the second lowest average farm acreage among the four segments; they were more likely than the other groups to include women; among the four segments, they were the least likely to be cooperative members; they had the second lowest education and family income levels; they were less likely to have a successor to take over the farm when they retired; and they were the least likely to collaborate with neighboring farmers on cropping practices that might affect them jointly. Farmers in this segment did not expect that UAVs can yield economic or environmental benefits on the farm, and they were, mostly, non-adopters of UAVs.

Overall, our analysis suggests strong segmentation of farmers based on their perceptions and expectations regarding the use and benefits of UAVs in agricultural production but also across their farm and personal characteristics. The four segments are quite distinct and our empirical results suggest that some $27 \%$ of the farmers in our sample who belong to the neighbor warry and the UAV technology detached segments are unlikely to adopt the technology. Most farmers in our sample (73\%), however, belong to the other two segments and are now or could become adopters of UAV technology as their characteristics make them potentially amenable to using the technology. This group of farmers is much larger than the one of current adopters and those that have indicated intention to adopt UAVs. Hence, there may be a significant latent 
demand for the technology beyond current adoption and stated intentions. In general then, our empirical results in this section not only paint a portrait of the adopter/potential adopter of the technology, but also provide a level of adoption that might be possible over time if the use of the technology becomes easier and the associated economic and environmental benefits become more apparent.

\subsection{Multinomial logit analysis of farm-level adoption}

In order to further analyze the current and prospective UAV farm-level adoption in our sample, we used multinomial logit analysis. Table 6 presents the relative risk rations (RRRs) from the multinomial logit model we used. ${ }^{3}$ An important question we had to answer first in our analysis was whether there were significant differences between current and prospective adopters in our sample. A likelihood ratio test rejected the null hypothesis at a $5 \%$ level that there is no distinction between the two groups $\left(\chi^{2}(36)=35.6\right)$. This implies that prospective and current adopters should be considered separate and distinct categories as additional information about the adoption of UAVs could be gleaned by maintaining such a grouping.

For the interpretation of the RRRs, we note here that RRRs greater (less) than 1 imply an increased (decreased) likelihood of belonging to the specific adopter group (prospective or current adopters) relative to the reference group (non-adopters). The estimated RRRs and their standard errors therefore indicate whether certain farm and farmer characteristics are either positively or negatively associated with the adoption or the intention to adopt UAVs.

${ }^{3}$ The coefficients of the multinomial logit are presented in Supplementary Table S3, for completeness and reader reference.

Table 6. Results of the multinomial logit model: relative risk ratios (RRR). ${ }^{1}$

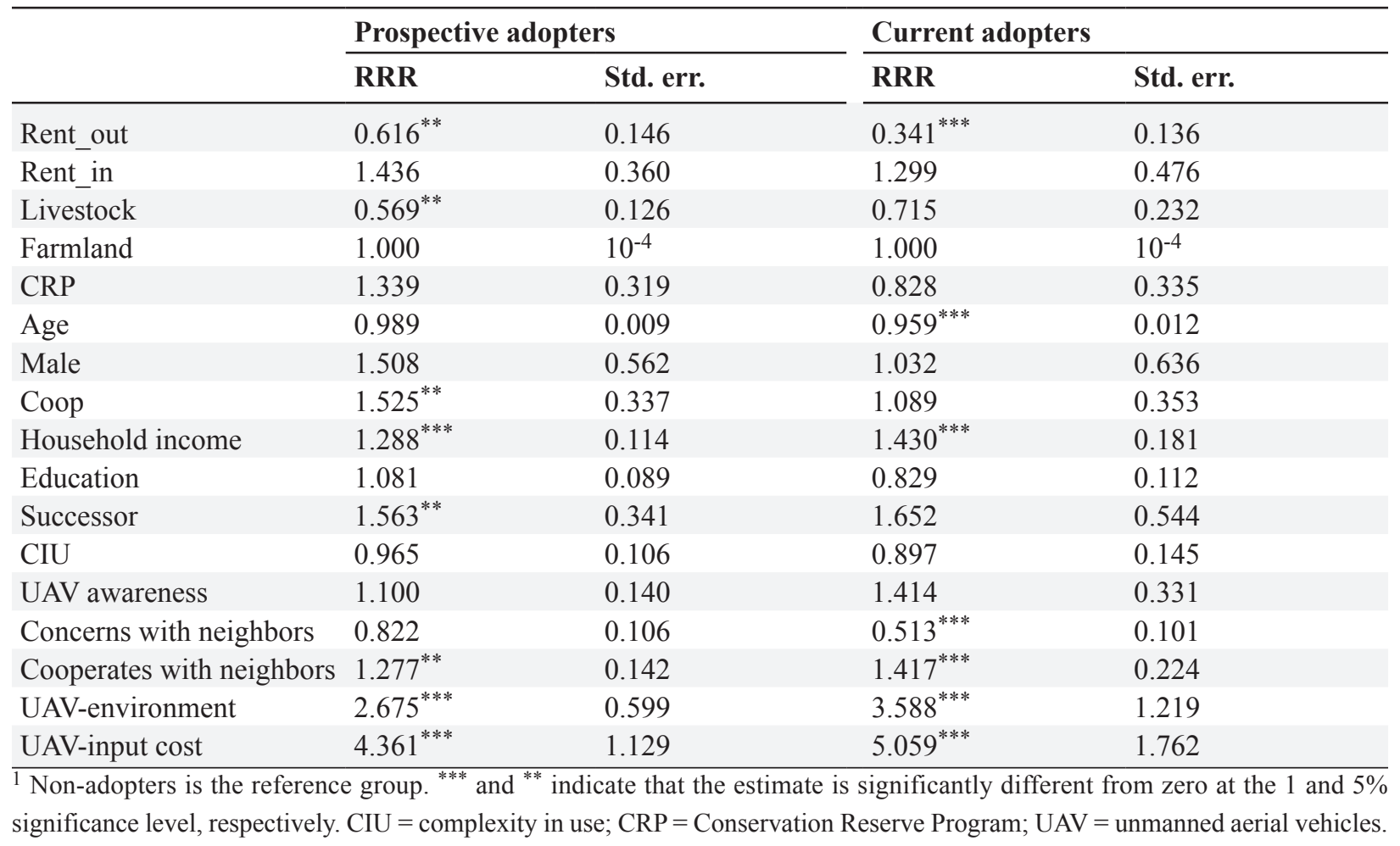


Our empirical results suggest that there are significant differences in the farmer and farm characteristics of current and prospective adopters, as a group, and non-adopters. These include farmer expectations for economic and environmental benefits from UAVs, household income, collaborative practices with neighboring farms and rent out land practices.

More specifically, farmers who perceive that the use of UAVs can lower their input costs and improve their profitability or that can help reduce the environmental footprint of their farm production were more likely to be current or prospective adopters of UAVs. In fact, these perceptions had the strongest impact on the likelihood of a farmer in our sample being an adopter of the technology. This result is in line with that of Zheng et al. (2019), who found that perceived usefulness of the UAV technology had a positive effect on Chinese farmers' intentions to adopt UAVs. Expected cost savings, productivity improvements, and/or environmental benefits have been found to be important drivers in adoption of various agricultural innovations (D'Antoni et al., 2012; Pivoto et al., 2019; Reimer et al., 2012; Skevas et al., 2013) and UAVs are therefore no different in that respect.

Family income was also positively associated with the likelihood that a farmer in our sample is either a current adopter or a prospective adopter of UAVs. This positive association of family income and technology adoption has also been reported in previous research on the adoption of agricultural innovations (Bayard et al., 2007; Skevas et al., 2013; Swinton et al., 2017). Having a higher income reduces the subjective cost of the innovation and the associated risks (Rogers, 2010) and often allows risk capital to be allocated to experimentation with new technologies, especially those that require an initial investment and additional spending on skill development.

Exchanging information and coordinating with neighboring farmers on agricultural production practices (e.g. planting and spray dates) was found to be associated with an increased likelihood that a farmer in our sample is current or prospective adopter of UAVs. Collaborating with neighboring farmers may be an indicator of progressiveness or openness and could facilitate communication and learning from others, all of which can encourage adoption of new technologies.

Renting out land was found to be associated with a diminished likelihood that a farmer in our sample is a current or prospective adopter. Renting out land to other farmers may be an indication that the farmer is less likely to grow or intensify its farming operation and hence less interested in UAVs. Another possible explanation is that, as farmers who rent out land become more passive participants in the farming operations, they leave UAV technology adoption to their tenants.

There were additional farmer and farm characteristics that were found to further differentiate current adopters from prospective adopters. More specifically, older age was found to be associated with lower likelihood that a farmer in our sample is a current adopter of UAVs. This result is in line with similar findings in previous studies of agricultural technology adoption (Barham et al., 2004; D'Antoni et al., 2012; Etriya et al., 2018; Feder et al., 1985; McBride and Daberkow, 2003). Older farmers may be less likely to invest in new technologies, such as UAVs, because of their short-time planning horizons.

Similarly, a higher level of perceived neighbor privacy concerns in the use of UAVs was found to be significantly associated with a reduced likelihood a farmer in our sample is a current adopter of UAVs. This result implies that farmers who might perceive a negative neighbor response to their technology choices can delay or defer adoption. Wollni and Andersson (2014) also found that social conformity plays an important role in farmer technology adoption decisions.

Our empirical results also identified additional farmer and farm characteristics that could further differentiate prospective adopters from non-adopters. In particular, raising livestock was also found to be associated with a reduced likelihood a farmer in our sample was a prospective adopter. Lack of crop specialization may provide a possible explanation. Still, in open-ended comments of our survey, a few farmers voluntarily offered that 
in some instances perceived that the noise of UAV operations could scare livestock and this could provide another explanation for the empirical result.

Cooperative membership was found to be associated with a higher likelihood a farmer in our sample would be a prospective adopter rather than a non-adopter. One possible explanation for this finding is that cooperatives expose farmers to new technologies and facilitate knowledge spillovers (Carrer et al., 2017), thus making farmers more receptive to innovations. Once again, this finding is consistent with similar findings in previous studies where a positive link between cooperative or association membership and technology adoption has been reported (Dill et al., 2015; Wossen et al., 2017).

Finally, availability of a successor on the farm was found to be associated with an increased likelihood that a farmer in our sample would be a prospective adopter of UAVs rather than a non-adopter. The presence of a successor may motivate farmers to invest in new technologies and improve the management of their farms, so that the successor can take over a more productive and profitable farm operation (Skevas et al., 2018).

It is worth noting that farmer awareness of UAV uses and applications ${ }^{4}$ was not found to be a statistically significant factor in the adoption decision. This result is not surprising since a great majority of the farmers in our sample were informed about UAV technology and its agricultural applications. Daberkow and McBride (2003) found a similar result in their study of precision agricultural technology adoption decisions in the US.

\section{Conclusions}

In this study we surveyed more than 800 Missouri farmers and explored their awareness of potential applications of UAVs in agriculture; their perceptions of technical complexities or other constraints on the use of UAVs; their expectations for the economic and environmental benefits from UAVs; and their willingness to adopt UAVs for their farming operations. Our data indicates that only $8 \%$ of the farmers in our sample were currently using UAVs on their farms while $19 \%$ of them had plans to adopt UAVs in the near future. The limited current adoption is not surprising given the early stages in the innovation cycle of UAVs.

Recognizing that farmers are heterogeneous, we used regression analysis to examine how individual farmer and farm characteristics are shaping current and future adoption of UAVs in agriculture. We found that the most significant driver of farmer adoption of UAVs is farmer expectations of potential economic and environmental gains from the use of UAVs. Socioeconomic farmer characteristics and farm characteristics also condition the adoption decisions of individual farmers as they modulate the incentives for adoption. Farmers with a long-term commitment to farming (e.g. younger farmers with long planning horizons, farmers with successors for the farm, and those preferring to be farmers rather than landlords, and farmers who cooperate with their neighbors) are more likely to be adopters or prospective adopters. High income farmers, with more access to risk capital, are also more likely to adopt UAVs. Raising livestock and farmer perceptions of neighbor privacy concerns were found to modestly discourage adoption. Awareness about the different applications of UAVs in agriculture was found to be high and did not seem to affect adoption or intention to adopt. At this time, specific information and empirical evidence on the potential economic and environmental benefits from UAVs would therefore be more important in encouraging farmer adoption.

In addition to using regression analysis to examine how farmer heterogeneity shapes their individual adoption decisions, we also used factor and cluster analysis to classify farmers into few homogeneous segments that might adequately describe general population tendencies in the adoption of UAVs. Using indicators of farmer awareness and perceptions towards UAV use, we classified Missouri farmers into four segments which we labelled: neighbor warry, UAV complexity warry, UAV technology savvy, and UAV technology detached.

\footnotetext{
${ }^{4}$ An endogeneity problem may arise when including this variable in the estimation of the multinomial logit model because UAV awareness is a precondition to the decision to adopt UAVs (Daberkow and McBride, 2003). To test for endogeneity of UAV awareness, a variable addition test was employed (Wooldridge, 2014). The test results (i.e. $\mathrm{x}^{2}(2)=2.434, P$-value $=0.297$ ) imply that we can be certain that the employed model that assumes the exogeneity of UAV awareness produces unbiased results.
} 
The neighbor warry and UAV technology detached segments, which account for only $27 \%$ of the farmers in our sample, were found to be less likely to adopt the technology in the long run. Most farmers (73\%), however, belonged to the UAV complexity warry and UAV technology savvy segments that included most of the current and prospective adopters. These two segments had such general farmer profiles that could become pools of adopters of UAVs in the future. The fact that these two segments together are much larger than the group of current and prospective adopters implies the potential presence of a latent demand for UAVs. Technology suppliers, service providers and public institutions could therefore unlock this latent demand and contribute to the adoption of UAVs in agriculture by engineering simplicity into the technology, reducing the costs associated with its use and providing strong evidence of its economic and environmental benefits on farmers' land.

\section{Acknowledgements}

This work was supported by the USDA National Institute of Food and Agriculture, Hatch project 1015805.

\section{Supplementary material}

Supplementary material can be found online at https://doi.org/10.22434/IFAMR2019.0151.

Table S1. Cluster means for attitudinal statements.

Table S2. Factor analysis on questions related to collaboration with neighboring farmers: rotated factor loadings.

Table S3. Coefficient estimates for multinomial logit model.

\section{References}

Aldana-Jague, E., G. Heckrath, A. Macdonald, B. Van Wesemael and K. Van Oost. 2016. UAS-based soil carbon mapping using VIS-NIR (480-1000 nm) multi-spectral imaging: potential and limitations. Geoderma 275: 55-66. https://doi.org/10.1016/j.geoderma.2016.04.012

Amemiya, T. 1981. Qualitative response models: a survey. Journal of Economic Literature 19(4): 1483-1536. Barham, B.L., J.D. Foltz, D. Jackson-Smith and S. Moon. 2004. The dynamics of agricultural biotechnology adoption: lessons from series rBST use in Wisconsin, 1994-2001. American Journal of Agricultural Economics 86(1): 61-72. https://doi.org/10.1111/j.0092-5853.2004.00562.x

Bayard, B., C.M. Jolly and D.A. Shannon. 2007. The economics of adoption and management of alley cropping in Haiti. Journal of Environmental Management 84(1): 62-70. https://doi.org/10.1016/j. jenvman.2006.05.001

Calinski, T. and J. Harabasz. 1974. A dendrite method for cluster analysis. Communications in Statistics 3: $1-27$.

Carrer, M.J., H.M. De Souza Filho and M.O. Batalha. 2017. Factors influencing the adoption of farm management information systems (FMIS) by Brazilian citrus farmers. Computers and Electronics in Agriculture 138: 11-19. https://doi.org/10.1016/j.compag.2017.04.004

Cheng, S. and J.S. Long. 2007. Testing for IIA in the multinomial logit model. Sociological Methods and Research 35(4): 583-600. https://doi.org/10.1177/0049124106292361

D'Antoni, J.M., A.K. Mishra and H. Joo. 2012. Farmers' perception of precision technology: the case of autosteer adoption by cotton farmers. Computers and Electronics in Agriculture 87: 121-128. https:// doi.org/10.1016/j.compag.2012.05.017

d'Oleire-Oltmanns, S., I. Marzolff, K.D. Peter and J.B. Ries. 2012. Unmanned aerial vehicle (UAV) for monitoring soil erosion in Morocco. Remote Sensing 4(11): 3390-3416. https://doi.org/10.3390/ rs4113390

Daberkow, S.G. and W.D. McBride. 2003. Farm and operator characteristics affecting the awareness and adoption of precision agriculture technologies in the US. Precision Agriculture 4: 163-177. https:// doi.org/10.1023/A:1024557205871 
Dill, M.D., G. Emvalomatis, H. Saatkamp, J.A. Rossi, G.R. Pereira and J.O.J. Barcellos. 2015. Factors affecting adoption of economic management practices in beef cattle production in Rio Grande do Sul state, Brazil. Journal of Rural Studies 42: 21-28. https://doi.org/10.1016/j.jrurstud.2015.09.004

Dillman, D.A., J.D. Smyth and L. Melani. 2011. Internet, mail, and mixed-mode surveys: the tailored design method. Wiley \& Sons, Toronto, Canada.

Duchsherer, C.J. 2018. On the profitability of UAS-based NDVI imagery for variable rate nitrogen prescriptions in corn and wheat in North Dakota. MSc-dissertation, North Dakota State University, Fargo, ND, USA.

Erickson, B. and J. Lowenberg-DeBoer. 2017. 2017 precision agriculture dealership survey. Departments of Agricultural Economics and Agronomy, Purdue University, West Lafayette, IN, USA.

Etriya, E., V.E. Scholten, E.F. Wubben, R.G. Kemp and S. Omta. 2018. The importance of innovation adoption and generation in linking entrepreneurial orientation with product innovation and farm revenues: the case of vegetable farmers in West Java, Indonesia. International Food and Agribusiness Management Review 21(7): 969-988. https://doi.org/10.22434/IFAMR2017.0038

Feder, G., R.E. Just and D. Zilberman. 1985. Adoption of agricultural innovations in developing countries: a survey. Economic Development and Cultural Change 33(2): 255-298. https://doi.org/10.1086/451461

Floreano, D. and R.J. Wood. 2015. Science, technology and the future of small autonomous drones. Nature 521: 460-466. https://doi.org/10.1038/nature14542

Freeman, P. and R. Freeland. 2014. Politics \& technology: US polices restricting unmanned aerial systems in agriculture. Food Policy 49: 302-311. https://doi.org/10.1016/j.foodpol.2014.09.008

Freeman, P.K. and R.S. Freeland. 2015. Agricultural UAVs in the US: potential, policy, and hype. Remote Sensing Applications: Society and Environment 2: 35-43. https://doi.org/10.1016/j.rsase.2015.10.002

Gago, J., C. Douthe, R. Coopman, P. Gallego, M. Ribas-Carbo, J. Flexas, J. Escalona and H. Medrano. 2015. UAVs challenge to assess water stress for sustainable agriculture. Agricultural Water Management 153: 9-19. https://doi.org/10.1016/j.agwat.2015.01.020

Huang, Y., S.J. Thomson, W.C. Hoffmann, Y. Lan and B.K. Fritz. 2013. Development and prospect of unmanned aerial vehicle technologies for agricultural production management. International Journal of Agricultural and Biological Engineering 6(3): 1-10. https://doi.org/10.3965/j.ijabe.20130603.001

Huuskonen, J. and T. Oksanen. 2018. Soil sampling with drones and augmented reality in precision agriculture. Computers and Electronics in Agriculture 154: 25-35. https://doi.org/10.1016/j.compag.2018.08.039

Kaufman, L. and P.J. Rousseeuw. 2009. Finding groups in data: an introduction to cluster analysis. John Wiley \& Sons, New York, NY, USA.

Läpple, D. and T. Van Rensburg. 2011. Adoption of organic farming: are there differences between early and late adoption? Ecological Economics 70(7): 1406-1414. https://doi.org/10.1016/j.ecolecon.2011.03.002

Long, S.J., J.S. Long and J. Freese. 2006. Regression models for categorical dependent variables using Stata. Stata press, College Station, TX, USA.

Martınez, J., G. Egea, J. Agüera and M. Pèrez-Ruiz. 2017. A cost-effective canopy temperature measurement system for precision agriculture: a case study on sugar beet. Precision Agriculture 18(1): 95-110. https://doi.org/10.1007/s11119-016-9470-9

McBride, W.D. and S.G. Daberkow. 2003. Information and the adoption of precision farming technologies. Journal of Agribusiness 21: 21-38. https://doi.org/10.22004/ag.econ.14671

Morley, C., J. Broadley, R. Hartley, D. Herries, D. McMorran and I. McLean. 2017. The potential of using Unmanned Aerial Vehicles (UAVs) for precision pest control of possums (Trichosurus vulpecula). Rethinking Ecology 2: 27-39. https://doi.org/10.3897/rethinkingecology.2.14821

Panagiotidis, D., A. Abdollahnejad, P. Surov and V. Chiteculo. 2017. Determining tree height and crown diameter from high-resolution UAV imagery. International Journal of Remote Sensing 38(8-10): 2392-2410. https://doi.org/10.1080/01431161.2016.1264028

Pivoto, D., B. Barham, P.D. Waquil, C.R. Foguesatto, V.F.D. Corte, D. Zhang and E. Talamini. 2019. Factors influencing the adoption of smart farming by Brazilian grain farmers. International Food and Agribusiness Management Review 22(4): 571-588. https://doi.org/10.22434/IFAMR2018.0086

Potts, S.G., P. Neumann, B. Vaissière and N.J. Vereecken. 2018. Robotic bees for crop pollination: why drones cannot replace biodiversity. Science of the Total Environment 642: 665-667. https://doi. org/10.1016/j.scitotenv.2018.06.114 
Primicerio, J., S.F. Di Gennaro, E. Fiorillo, L. Genesio, E. Lugato, A. Matese and F.P. Vaccari. 2012. A flexible unmanned aerial vehicle for precision agriculture. Precision Agriculture 13(4): 517-523. https://doi.org/10.1007/s11119-012-9257-6

Pritt, M.D. 2014. Fast orthorectified mosaics of thousands of aerial photographs from small UAVs'. In: Proceedings of 2014 IEEE Applied Imagery Pattern Recognition Workshop (AIPR). October, 2014. Washington, DC, USA, pp. 1-8. https://doi.org/10.1109/AIPR.2014.7041928

Psirofonia, P., V. Samaritakis, P. Eliopoulos and I. Potamitis. 2017. Use of unmanned aerial vehicles for agricultural applications with emphasis on crop protection: three novel case studies. International Journal of Agricultural Science and Technology 5(1): 30-39. https://doi.org/10.12783/ijast.2017.0501.03

Reimer, A.P., D.K. Weinkauf and L.S. Prokopy. 2012. The influence of perceptions of practice characteristics: an examination of agricultural best management practice adoption in two Indiana watersheds. Journal of Rural Studies 28(1): 118-128. https://doi.org/10.1016/j.jrurstud.2011.09.005

Rogers, E.M. 2010. Diffusion of innovations. The Free Press, New York, NY, USA.

Schirrmann, M., A. Giebel, F. Gleiniger, M. Pflanz, J. Lentschke and K.-H. Dammer. 2016. Monitoring agronomic parameters of winter wheat crops with low-cost UAV imagery. Remote Sensing 8(9): 706. https://doi.org/10.3390/rs8090706

Skevas, T., E.M. Kikulwe, H. Papadopoulou, I. Skevas and J. Wesseler. 2013. Do European Union farmers reject genetically modified maize?: farmer preferences for genetically modified maize in Greece. AgBioForum 15(3): 242-256.

Skevas, T., F. Wu and Z. Guan. 2018. Farm capital investment and deviations from the optimal path. Journal of Agricultural Economics 69(2): 561-577. https://doi.org/10.1111/1477-9552.12252

Swinton, S.M., S. Tanner, B.L. Barham, D.F. Mooney and T. Skevas. 2017. How willing are landowners to supply land for bioenergy crops in the Northern Great Lakes Region? GCB Bioenergy 9(2): 414-428. https://doi.org/10.1111/gcbb.12336

Tey, Y.S. and M. Brindal. 2012. Factors influencing the adoption of precision agricultural technologies: a review for policy implications. Precision Agriculture 13(6): 713-730. https://doi.org/10.1007/ s11119-012-9273-6

Thompson, N.M., C. Bir, D.A. Widmar and J.R. Mintert. 2019. Farmer perceptions of precision agriculture technology benefits. Journal of Agricultural and Applied Economics 51(1): 142-163. https://doi. org/10.1017/aae.2018.27

Vega, F.A., F.C. Ramirez, M.P. Saiz and F.O. Rosua. 2015. Multi-temporal imaging using an unmanned aerial vehicle for monitoring a sunflower crop. Biosystems Engineering 132: 19-27. https://doi. org/10.1016/j.biosystemseng.2015.01.008

Walter, A., R. Finger, R. Huber and N. Buchmann. 2017. Opinion: smart farming is key to developing sustainable agriculture. Proceedings of the National Academy of Sciences 114(24): 6148-6150. https://doi.org/10.1016/j.biosystemseng.2015.01.008

West, G. and K. Kovacs. 2017. Addressing groundwater declines with precision agriculture: an economic comparison of monitoring methods for variable-rate irrigation. Water 9(1): 28. https://doi.org/10.3390/ w9010028

Wollni, M. and C. Andersson. 2014. Spatial patterns of organic agriculture adoption: evidence from Honduras. Ecological Economics 97: 120-128. https://doi.org/10.1016/j.ecolecon.2013.11.010

Wooldridge, J.M. 2014. Quasi-maximum likelihood estimation and testing for nonlinear models with endogenous explanatory variables. Journal of Econometrics 182(1): 226-234. https://doi.org/10.1016/j. jeconom.2014.04.020

Wossen, T., T. Abdoulaye, A. Alene, M.G. Haile, S. Feleke, A. Olanrewaju and V. Manyong. 2017. Impacts of extension access and cooperative membership on technology adoption and household welfare. Journal of Rural Studies 54: 223-233. https://doi.org/10.1016/j.jrurstud.2017.06.022

Zhang, C. and J.M. Kovacs. 2012. The application of small unmanned aerial systems for precision agriculture: a review. Precision Agriculture 13(6): 693-712. https://doi.org/10.1007/s11119-012-9274-5

Zheng, S., Z. Wang and C.J. Wachenheim. 2019. Technology adoption among farmers in Jilin Province, China: the case of aerial pesticide application. China Agricultural Economic Review 11(1): 206-216. https://doi.org/10.1108/CAER-11-2017-0216 
